\title{
Hybrid Method and Similarity to Recognize Javanese Keris
}

\author{
Halim Budi Santoso \\ Faculty of Information Technology \\ Duta Wacana Christian University \\ Yogyakarta, Indonesia
}

\author{
Ryan Peterzon Hadjon \\ Faculty of Information Technology \\ STIKOM Uyelindo \\ Kupang, Indonesia
}

\begin{abstract}
This paper describes Hybrid method and Similarity for recoginizing Javanese Keris. Javanese Keris is one of traditional javanese weapon. It is one of the Indonesia Cultural Heritage. Keris is famous for its distinctive wavy blade. But some of the keris has straight blades. There are many kinds of Keris and every Keris has its own unique pattern. The algorithm to recognize several types of Javanese Keris is made by using Edge Detection method with Image Segmentation and combine with Similarity. By using these three methods, it will bring more exact results.

The method combines Canny Algorithm and Basic Morphological for image segmentation. The result of edge detection and image segmentation are compared with the sample pictures using similarity. Ten (10) images of traditional javanese keris are being used as samples. The final result for this study is recognizing the kind of keris. These techniques is carried out with an experiment by using MATLAB 6.0.1 software.
\end{abstract}

Keywords-Edge Detection; Similarity; Canny Algorithm; Basic Morphological; Image Recognition; Javanese Keris

\section{INTRODUCTION}

Edge detection is one of the image processing techniques to identify the real edge of an image. The purpose is to get detail information of an object in an image by detecting the edge of the object and separating the image background with the object [1].

The edges of an image are the boundary for every different texture [2]. Many algorithms have been developed in various research to detect edge [2] [3] [11] [12]. One of the edge detection algorithms is Canny Algorithm.

Canny Algorithm is an effective algorithm to detect the edge of an object because the result of this method can produce single pixel thick.Using this method also can detect continous edge, comparing with other edge detection algorithms [3]. This algorithm can be used to recognize the object within an image. In his research, Allam Mouse [4] develop an alogorithm to recognize license number plate using Canny Algorithm for edge detection.

In this research, Canny algorithm is combined with the basic morphological method for image segmentation. Image segmentation is a process to divide an image into smaller segment (collection of pixel or superpixel). The objective of image segmentation is to identify relevant objects in digital image [5] [6]. Image segmentation has been used in many image processing application or computer vision. Using combination of edge detection and image segmentation can produce more exact results comparing with only one algorithm, either edge detection or image segmentation.

The result of image segmentation and edge detection is combined by using similarity models to recognize image of javanese keris. Many studies have been conducted to find the similarity of two or more images [13][14][19]. One of the study was did by C.M. Christopher [7]. C.M. Christopher, et al. study about recognizing 3D objects using graf approach and similarity. As the result, they found an effective method to recognize 3D objects using similarity model.

The arrangement of this paper as follows. In the second section, the edge detection using Canny Algorithm and image segmentation using Basic Morphological are discussed.. Similarity models is also discussed in this section. Following the literature review is literature study about Javanese Keris and its kind. In the fourth section, analyzing the image using the selected methods. The result of this study is discussed in this section. Following the result, the conclusion is written in the last section.

\section{LITERATURE REVIEW}

\section{A. Keris as Indonesian Cultural Heritage}

Keris is one of the Indonesian traditional weapon. In the past, Keris was the heritage from Dongson and South China Culture $^{1}$. Based on the literature, Dong Son civilization brought metal work knowledge to the Malay World. It is known for its elaborative bronze working, especially its drum. People called it Keris Sajen since the leaf shaped blades of the Dong Son Daggers looked like a Keris.

In the Empire age of Indonesia, such as Majapahit, Keris was used as a weapon for civil society. Keris was well known as a weapon which had strong, tough, and light blade. In the era of Demak - Mataram kingdom, the most famous Keris was Keris Nagasasra Sabukinten.

Nowadays, Keris has totally different function comparing in the past time. People think that Keris is "Tosan Aji" not a weapon. Different regions in Indonesia has a different perspective about Keris and the usage of Keris. Javanese culture thinks that Keris is a dhuwung or a relic.

\footnotetext{
${ }^{1}$ http://old.blades.free.fr/keris/introduction/origin/history2.htm. Data accessed on $8^{\text {th }}$ August 2015.

${ }^{2}$ Tosan aji is a kind of metal which is glorious and honorable.
} 
Keris has unique pattern comparing with other traditional weapon. Keris looks like a dagger. Some of Keris have wavy blades and the other have straight blade. Many kinds of Keris comes from different region of Indonesia. There are two main parts of Keris, Warangka and Wilah.

Warangka is a Keris Sheath. Warangka is made from various kind of materials, but most of them are made from wood to hold the blade which can be coated with metals, such as brass, iron, silver,or gold. The upper part of sheath formed a broad curved handle made from wood or sometimes ivory. It could be adorned with precious and semi-precious stones. One of the Javanese keris in 1881, the Shealth is made from silver and the front have leaf and floral shaped chasing [20].

Another part of Keris is Wilah. Wilah is the Keris blade. Keris blades are ussually narrow with a wide, asymmetrical base. It has Luk. Luk is a wave in Keris. Common Keris has odd number of luk, range from three to thirteen waves, but some blades have up to $29 .{ }^{3}$ One of the examples is North Java Keris that have eleven curves in its blade [20].

The last part of Keris is Hulu Keris or it is called Hilt. Hilt is the object of art, often craved in meticulous details and made from various materials; precious rare types of wood to gold or ivory ${ }^{4}$. They were often craved to resemble demons coated in gold and adorned with semi precious and precious stone, such as rubies. In Yogyakarta, one of its keris has hilt based on the face of the owner [20].

\section{B. Canny Algorithm}

One of the algorithm to detect image edge in image processing is Canny Algorithm or Canny Edge Detector. Canny Algorithm is known as one of the optimal algorithm to detect edge in digital image. This algorithm was introduced by John Canny in 1986 on his thesis to finish his master degree in MIT [10]. Canny Algorithm was developed to make a new optimal method to detect edge by modifying the existing algorithm [2] [6].

Canny Algorithm is specified to optimize edge detection method in two (2) criteria specific which has to be fulfilled. The first criteria is edge detection method has to have an appropiate signal - to - noise ratio in order to be implemented in bad quality image. In other word, an Edge Detection method should have low error ratio. Every edge in digital image has not to be missed and every non edge shape has not to be responded [2].

The second criteria that every edge in image has to be located properly. It means that distance between edge pixels has to be detected and the real edge should be minimized well. There are some steps to use Canny Algorithm :

- Reduce all of noises using Gaussian Filter in the following equation:

$$
\boldsymbol{g}(\boldsymbol{m}, \boldsymbol{n})=\boldsymbol{G} \sigma(\boldsymbol{m}, \boldsymbol{n}) * \boldsymbol{f}(\boldsymbol{m}, \boldsymbol{n})
$$

Where $\boldsymbol{G} \boldsymbol{\sigma}(\boldsymbol{m}, \boldsymbol{n})$ can be expressed as follows:

\footnotetext{
${ }^{3}$ http://www.karatonsurakarta.com/keris.html. Data accessed in $10^{\text {th }}$ August 2015.

${ }^{4} \mathrm{http}: / /$ www.javakeris.com/?mode=viewid\&post_id=61. Data accessed in 10th August 2015.
}

$$
G \sigma(m, n)=\frac{1}{\sqrt{2 \pi \sigma^{2}}} \exp \left[\frac{-m^{2}+n^{2}}{2 \sigma^{2}}\right]
$$

- Calculate gradient $g(m, n)$ using one of the existing gradient operators to get:

and

$$
M(m, n)=\sqrt{g m^{2}(m, n)+g n^{2}(m, n)}
$$

$$
\theta(m, n)=\arctan \left[\frac{\operatorname{gn}(m, n)}{\operatorname{gm}(m, n)}\right]
$$

- Define threshold $M$ using the following equation:

$$
\boldsymbol{M}_{T}(\boldsymbol{m}, \boldsymbol{n})=\left\{\begin{aligned}
\boldsymbol{M}(\boldsymbol{m}, \boldsymbol{n}), & M(\boldsymbol{m}, \boldsymbol{n})>T \\
\mathbf{0 ,} & M(\boldsymbol{m}, \boldsymbol{n})<T
\end{aligned}\right.
$$

Where $\mathrm{T}$ is defined in order to save all of the edge and only reduce the noise.

- Surpress Non-Maxima pixel on the $\mathbf{M}_{\mathbf{T}}$ edge which is got from (3) equation to thin the edge line.

- Hysteresis: apply the threshold to supressed image. Canny algorithm is able to use two (2) thresholds, upper and lower threshold.

- If gradient of pixel is bigger than upper threshold then pixel is detected as an edge.

- If gradient of pixel is lower than lower threshold then pixel cannot be accepted / is refused as an edge.

$\circ$ If the value of pixel gradient between those two thresholds, this pixel is not detected as an edge unless the edge is connected to the pixel which is in above the upper threshold.

\section{Basic Morphological Method}

In the digital image processing, morphology is one of the methods to analyze the geometrical structure which stick on the image. Morphology is based on the association theory in mathematics [9][15]. In general, morphological method can be used as an image segmentation method. The goal of this method is to change the original image into new image through an interaction with another image which has specific shape and size. Image geometric feature which has the same size and shape will be saved. The rest of them will be neglected. This process is known as structuring element. In the digital image, collection of pixel which is similar (geometric feature with the same shape and size) is known as "foreground" (pixel structure has value one (1)) [8] and collection of pixel which is the complement is known as background (pixel structure has value 0) [8]. According to Basic Morphological or Morphology, there are some basic arithmetic which can be used for image segmentation [9][16].

1) Dilation : if $A$ and $B$ is the element of $Z 2$ association then dilation of $A$ by $B(A \oplus B)$ can be expressed as follow: $\underset{\text { Or }}{\mathbf{A} \oplus \mathbf{B}}=\left\{\mathbf{z} \in \mathbf{Z}^{2} \mid \mathbf{z}=\mathbf{a}+\mathbf{b}\right.$, for some $\mathbf{a} \in \mathbf{A}$ and $\left.\mathbf{b} \in \mathbf{B}\right\}$

$\mathrm{A} \oplus \mathrm{B}=\mathrm{U}_{b \in B}(A)_{b}$

Dilation is the process to expand the image so if there are some holes in the foreground will be filled. 
2) Erosion : Erotion of image $A$ by structuring element $B$ can be denoted $A \Theta B$ is:

$$
\underset{\text { Or }}{\mathbf{A \Theta B}}=\{\mathbf{z} \mid \mathbf{z}+\mathbf{b} \in \mathbf{A} \text {, for all } \mathbf{b} \in \mathbf{B}\}
$$

$$
\mathrm{A \Theta B}=\bigcap_{b \in B}(\boldsymbol{A})_{-b^{C}}
$$

The result of erotion process is the opposite of the dilation where erotion will make the original picture smaller and eliminate small noises which is not required in "foreground".

3) Opening: Opening of image A by structuring element $B$ can be denoted $A \circ B$ is expressed as follows:

\section{$\mathbf{A} \circ \mathbf{B}=(\mathbf{A} \Theta \mathbf{B}) \oplus \mathbf{B}$}

The result of opening process is smoothing image processing and reduce the noise from quantitation or extra structure in the original image.

4) Closing : Closing of image A by stucturing element $B$ can be denoted $A \cdot B$ is expressed as follows:

\section{$\mathbf{A} \cdot \mathbf{B}=(\mathbf{A} \oplus \mathbf{B}) \boldsymbol{\Theta} \mathbf{B}$}

The result of closing process is the additional pixel on the holes in the original image and smoothing process like in the opening process.

\section{Similarity Concept}

Similarity concept is the basic geometric concept in mathematics that expressed the similarity of two (2) objects. Two (2) objects are similar if those two objects has the same shape. In other words, there is no significant differences between the two objects geometrically [18][19]. Calculating similarity between two objects is one of the key objectives in the image recognizition. To calculate the similarity degree, there is an involvement with resemblance within the two objects using similarity measure. [17].

Shape similarity measure or distance function in the shape association $\mathrm{S}$ is the function of $\mathrm{d}: \mathrm{S} \times \mathrm{S} \rightarrow \mathrm{R}$. There are some conditions that have to be fulfilled for the shape $\mathrm{A}, \mathrm{B}$, or $\mathrm{C}$ in $\mathrm{S}$ as follows [18]:

1) (Non-negativity): $d(A, B) \geqslant 0$

2) (Identity): $d(A, A)=0$, for all of the shape $A$

3) (Uniqueness): $d(A, B)=0$, so $A=B$

4) (Strong triangle inequality): $d(A, B)+d(A, C) \geqslant d(B, C)$.

5) (Triangle inequality): $d(A, B)+d(B, C) \geqslant d(A, C)$.

6) (Relaxed triangle inequality): $c(d(A, B)+d(B, C)) \geqslant$ $d(A, C)$, for $c \geqslant 1$

7) (Symmetry): $d(A, B)=d(B, A)$

8) (Invariance): $g \in G, d(g(A), g(B))=d(A, B)$.

9) (Pertubation robustness): $d(f(A), A)<\in d(B, A)$ for all $f$ $\in F$.

10)(Crack robustness): $A-U=B$ - $U$, where $d(A, B)<\in$

11)(Blur robustness): $d(A, B)<\in$ for all $B$ that $B-U=A-U$ and $d(A, B)<\in$.

12)(Noise robustness): for all $x \in R^{\wedge} 2$ dan $\in>0$, there is $U$ from $x$ in order for every $B$ this formula is valid $B-U=A$ $U$, where $d(A, B)<\in$.

13)(Distributivity): for every $A$ and decomposition $B \cup C$, $d(A, B \cup C) \leqslant d(A, B)+d(A, C)$.
14)(Endlessness): for every $A, B$ there is $C$ where $d(A, C)>d(A, B)$.

15)(Discernment): for every transformation association $G$ which is chosen, $d(A, A \cup B) \leqslant d(g(A), A \cup B)$ where $g \in G$.

16)(Sensitivity): for every $A, B$ with $A \cap B=B \cap A, B-U=C$ $U$, and $B \cap U \neq C \cap U$ for every $U \subset R^{\wedge} 2$, then $d(A, B)<d(A, C)$.

17)(Proportionality): for every $A \cap B=\varnothing$ and $A \cap C=\varnothing$, if $B \subset C$, then $d(A, A \cup B)<d(A, A \cup C)$.

18)(Monotonicity): for all $A \subset B \subset C, d(A, C)>d(A, B)$, or $d(A, C)>d(B, C)$.

\section{PROPOSED ALGORITHM}

In this study, the writers try to develop a hybrid algorithm as a combination between Canny Edge Detection and Image Segmentation using the Basic Morphological Method. After using the hybrid method, the segmented image will be compared with the sample pictures of keris.

In order to use this algorithm, some preparation should be done to change the original image into the same dimensions. These ten (10) images will be used as a reference to be compared with the tested image:

1) Take 10 samples of Keris from different regions in Java

2) Normalize these ten (10) samples of keris, including resize the image to get desired pixel and crop some background

3) Rotate the picture in order to get the image in a vertical position with Wilah is in the top position and hulu is under the blade.

4) Use the Canny Algorithm for image detection.

5) Use the Basic Morphological Algorithm to segment the image.

The sample of preparation can be seen in figure 1 below:

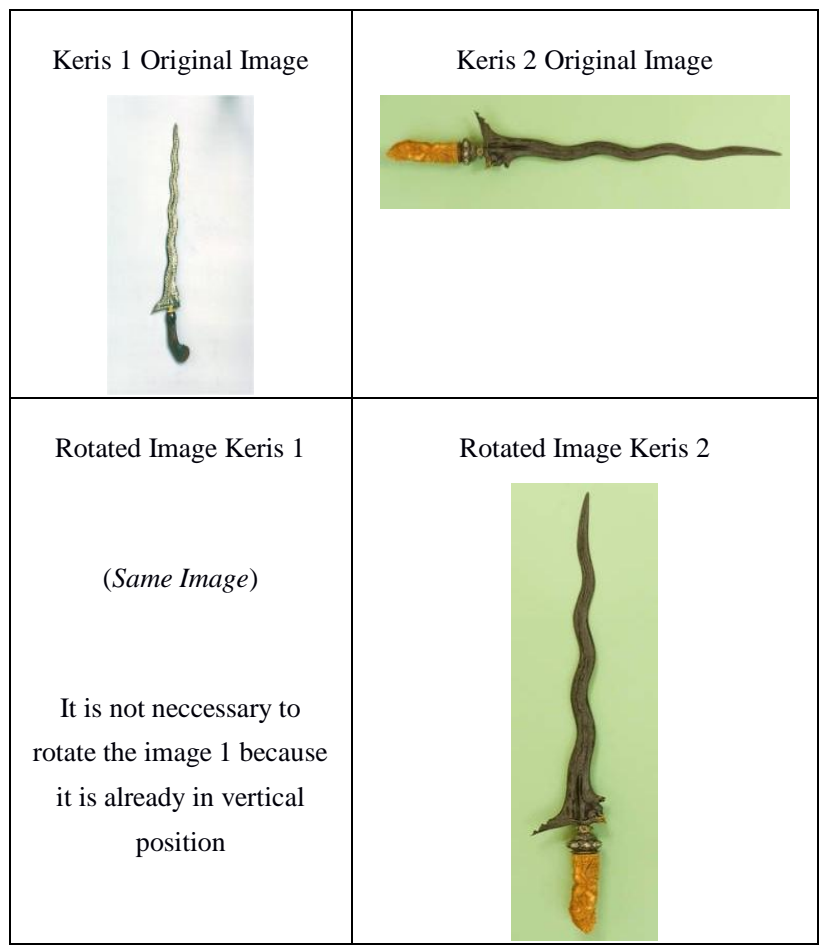




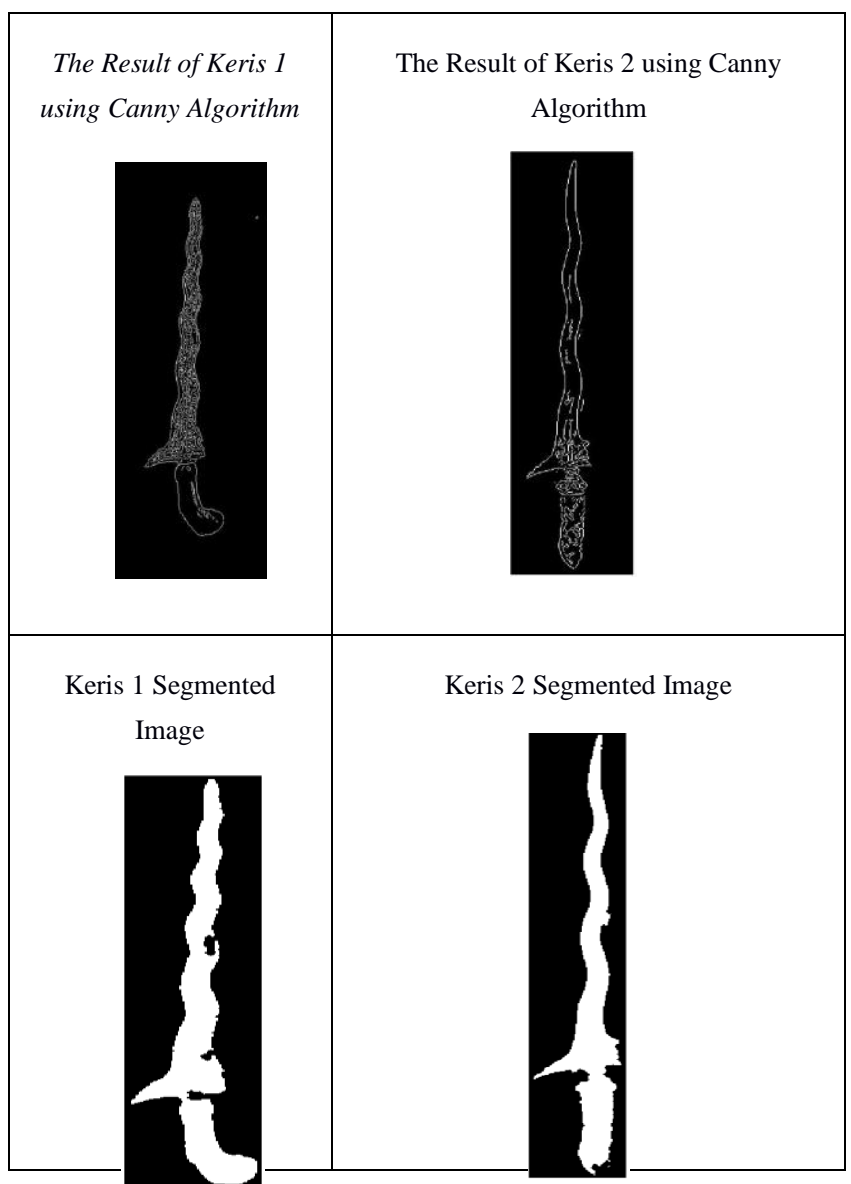

Fig. 1. The Result of Sample Keris Preparation

After some steps to prepare ten (10) samples picture of Keris, here is the algorithm which is used to recognize Javanese Keris.

1) Do the preparation steps as mention above

2) Similarity testing by comparing the vector of tested image with sample image

3) Calculate the total pixel which has same value between tested image and sample image

4) Calculate the total pixel of every picture

5) Calculate the percentage similarity between tested image and sample image

6) Define the keris using the highest percentage

\section{IMAGE SimULATION}

In this study, ten (10) sample of keris images are used. All of those Keris have been known the origin. Based on Groneman [20] there are some Keris from different parts of Java Island. The ten (10) samples are taken from book [20]. The research is conducted by using those ten (10) samples. As tested images, three (3) unknown Keris are taken. Recognizition keris process is done using some primary steps based on algorithm above mentioned in section three (3).

\section{A. Normalize the Image to get the same dimension.}

Normalization is done to ease the similarity process since it is required the same dimension to be compared. Image normalization is done by changing the image size and tested image. The result is the same dimension of the sample and tested image. The image size is 85 pixel for width and 507 pixel for length.

In figure 2, it shows the three tested Keris Image. In Figure 3 , it shows the ten sample Keris image.

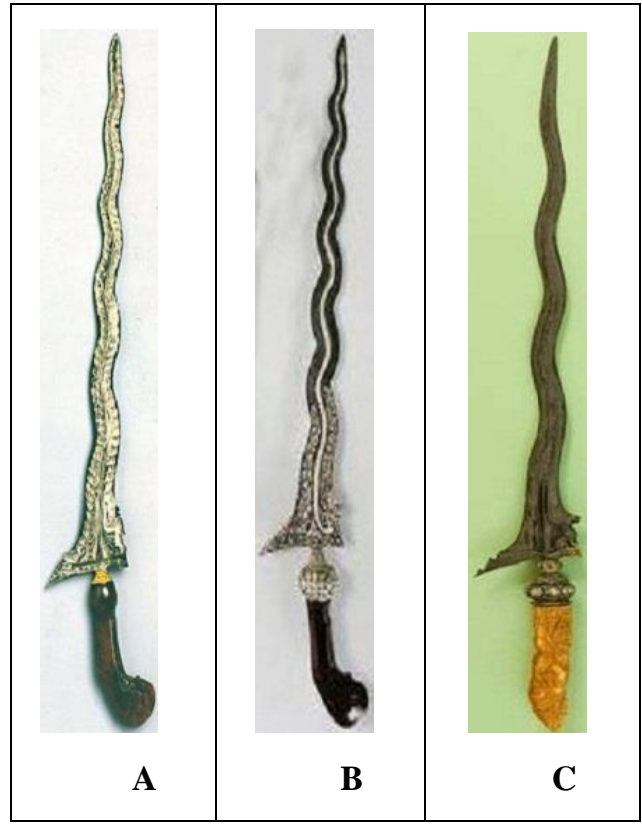

Fig. 2. Unknown Tested Keris image A, B, and C

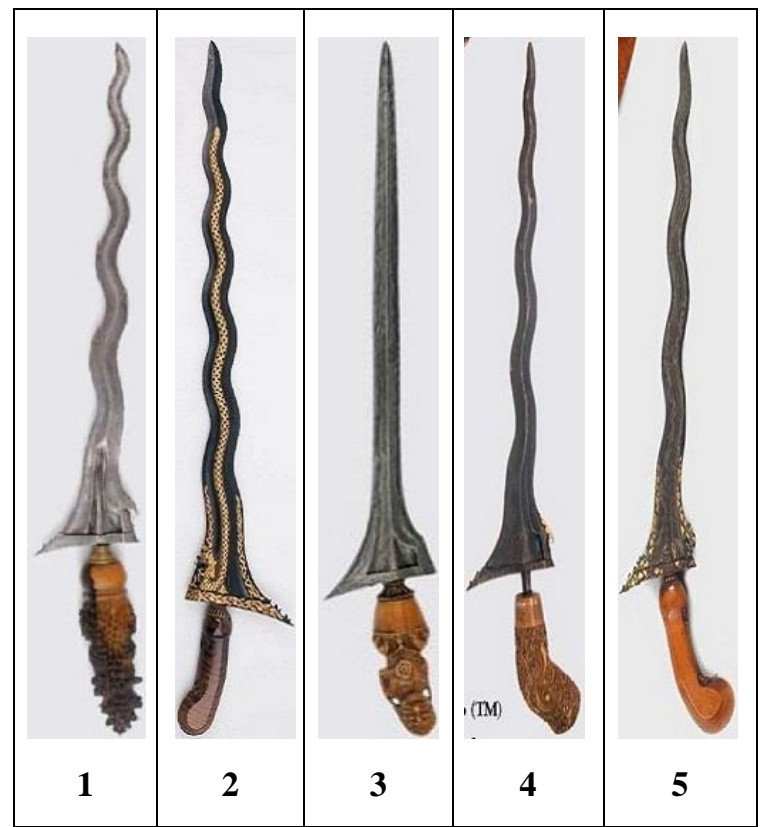




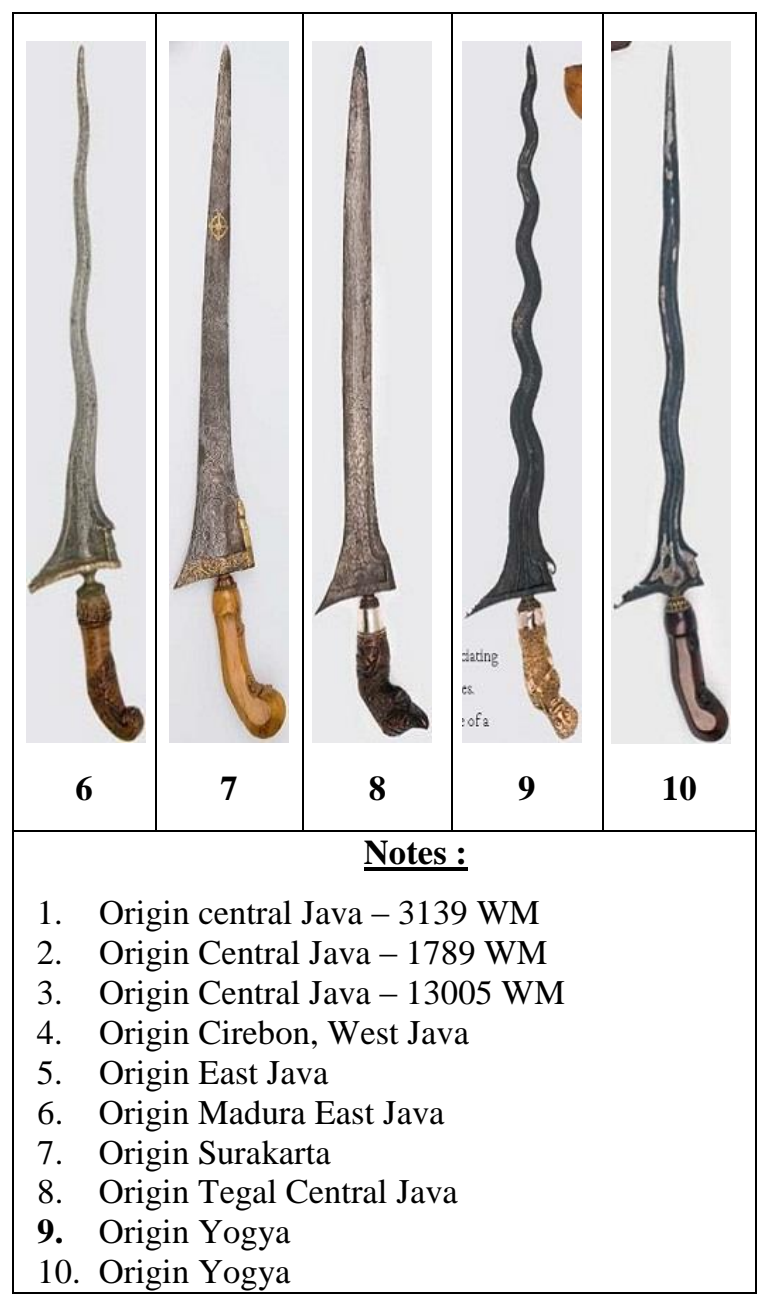

Fig. 3. Ten Sample Keris Image

After the rotation (if needed), the next step is to make the same dimensions for every Keris Image. Each Keris Image in Figure 2 and Figure 3 has the same dimensions. 85 × 507 pixels. Keris image has been standardized to make the same dimension for every picture.

\section{B. Edge Detection and Image Segmentation for every Keris Image}

Before doing this step, canny edge detection algorithm and basic morphological image segmentation is done for ten (10) sample keris images and three (3) tested keris image.

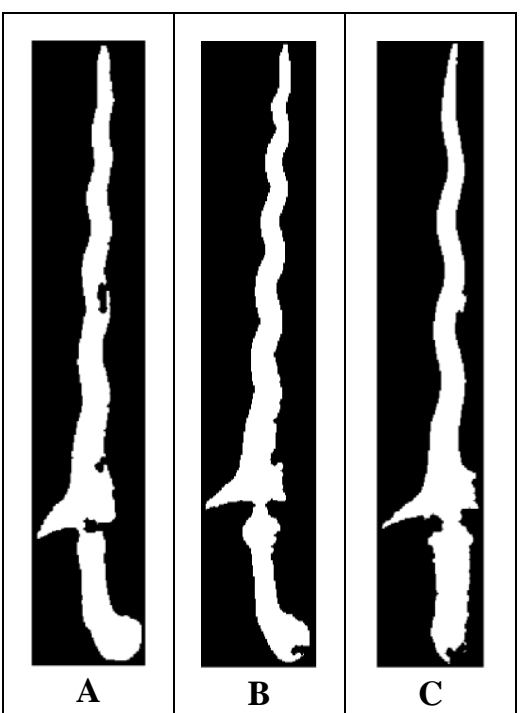

Fig. 4. Tested Image $\mathrm{A}, \mathrm{B}$, and $\mathrm{C}$ after Edge Detection and Image Segmentation

Figure 4 above gives the result of tested image A, B, and C after two operations: Edge Detection and Image Segmentation were conducted. On the other hand, Figure 5 below shows the result of sample image keris 1 to 10 after Edge Detection and Image Segmentation has been done to the Images.

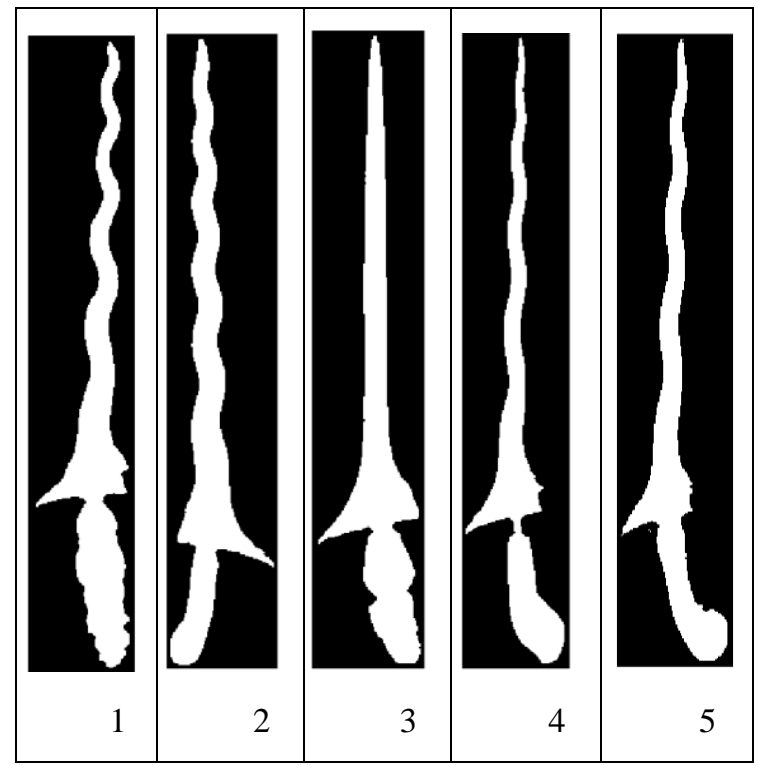




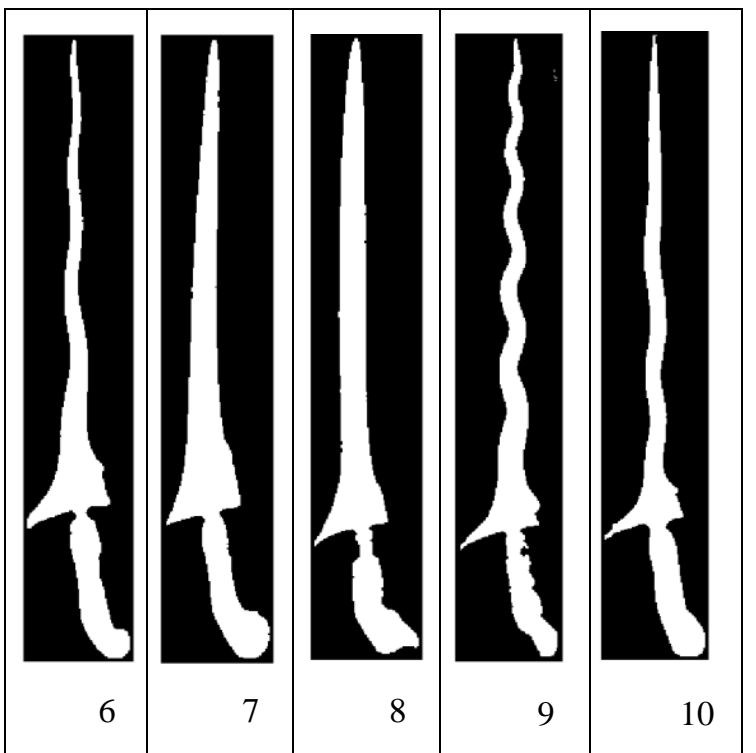

Fig. 5. After Image Detection of Keris Sample Image 1-10

\section{Image Similarity to compare between two similar images.}

In this process, sample and tested images are into a single vector which has value 0 (black) or 1 (white). It is to ease the comparison for every pixel in the image, either sample or tested image. Every pixel in image A, B, and C has to be converted into a vector. There is a counter for every testing which shows the total pixel has the same value within two images, tested and sample image. The result will be used to calculate image similarity. The result is an input for the next process, calculating the image similarity percentage.

After the total same pixel is derived, the calculation of similarity percentage is the next step. Percentage of image similarity within two image is the total same pixel (number of pixel between two images, tested and sample image which have same value) is divided by the total pixel.

The result of calculation using similarity percentage can be seen in Table 1 below. From the table 1, it can be seen that the highest percentage for every image will be different.

TABLE I. Similarity Result BetweEn TeSTED IMAGE AND SAMPLE IMAGE

\begin{tabular}{|c|c|c|c|c|}
\hline \multicolumn{2}{|c|}{ Similarity Percentage } & \multicolumn{3}{|c|}{ Tested Image } \\
\hline & & Image A & Image B & Image C \\
\hline \multirow{10}{*}{ 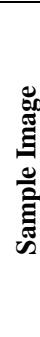 } & Image 1 & 74.50 & 80.87 & 88.17 \\
\hline & Image 2 & 65.34 & 65.34 & 58.35 \\
\hline & Image 3 & 86.47 & 83.11 & 79.68 \\
\hline & Image 4 & 88.35 & 83.24 & 71.46 \\
\hline & Image 5 & 86.05 & 81.62 & 67.38 \\
\hline & Image 6 & 83.58 & 82.16 & 72.74 \\
\hline & Image 7 & 76.85 & 75.45 & 64.39 \\
\hline & Image 8 & 73.78 & 71.67 & 61.85 \\
\hline & Image 9 & 87.88 & 85.12 & 75.61 \\
\hline & Image 10 & 65.34 & 82.42 & 73.25 \\
\hline
\end{tabular}

\section{Intrepret the Result of Calculation}

In this step, the highest percentage is taken to define the kind of Keris. Based on table 1, it can be concluded that:
1) Image A has the highest percentage value (88.35\%) with Image 4. It means that Image $A$ is most similar with Image 4. It can be concluded that Keris A is most similar with Keris sample 4 (Keris from Cirebon, West Java). This number also shows that Keris A is possibly recognized as Keris from Cirebon, West Java.

Image A only has $73.78 \%$ with Keris image 8 . It means that Image A is less similar to Keris image 8 (Keris from Tegal, Central Java)

2) Image $B$ has the highest percentage value (85.12\%) with Image 9. It means that Image $B$ is similar to Image 9. It can be concluded that Keris B is similar with Keris 9 (Keris from Yogyakarta).

Image B only has $75.45 \%$ with Keris image 7. It means that Image B is less similar to Keris image 7 (Keris from Surakarta, Central Java).

3) Image $C$ has the highest percentage value (88.17\%) with Keris image 1. It can be concluded that Keris $C$ is most similar with Keris 1 (Keris from Central Java) and possibly can be recognized as Keris from Central Java.

\section{CONCLUSION}

Keris recognition is one of the image recognition applications. Proposed algorithm that is used in this research is able to recognize the kind of Keris based on the calculation of every single pixel on the Keris's image after being converted into a single vector. The higher similarity percentage value, more accurate the possibility of the keris recognizition. The higher similarity percentage value will give more confident result.

On the other hand, the result of similarity calculation depends on the result of image segmentation. Better result of image segmentation will bring better result to the calculation for image similarity. Basic Morphological methods is one of the suitable image segmentation method to Keris segmentation. In the next research, it is suggested to use another image segmentation to compare the result with Basic Morphological Methods.

Some limitation in this study also need to be fixed. The similarity percentage still lower than $90 \%$. It is needed to be higher than $90 \%$. The other algorithm can be implemented to test the Javanese Keris.

For further research, some improvement can be done. It is better to test the image from the picture taken from the original Keris. There are many museum that has Keris collections, such as Museum Pusaka in Jakarta, Museum Sonobudoyo in Yogyakarta, Keris Museum in Surakarta. The algorithm can be tested to test the photograph taken from those museum. It is suggested to combine with the mobile application to recognize Javanese Keris. The reader can also have the history of the Keris from those mobile application.

Indonesia has many traditional weapons. It is also applicable that this algorithm can be test to recognize other traditional weapons, such as Mandau from Borneo. 


\section{REFERENCES}

[1] Al-amri, S. Salem, N.V. Kalyankar, S.D. Khamitkar (2010). "Image Segmentation by Using Edge Detection". International Journal on Computer Science and Engineering, vol. 2(3), 804-807.

[2] Juneja, M., P. Singh Sandhu (2009). "Performance Evaluation of Edge Detection Techniques for Images in Spatial Domain". International Journal of Computer Theory and Engineering, vol. 1 (5), 1793-8201.

[3] Nadernejad, E., S.Sharifzadeh, and H. Hassanpour (2008). "Edge Detection Techniques : Evaluations and Comparisons". Applied Mathematical Sciences, vol. 2 (31), 1507-1521.

[4] Allam, M (2012). "Canny-Edge Detection Based Vehicle Recognition", International Journal of Signal Processing, Image Processing and Pattern Recognition, vol. 5 (3).

[5] Nagaraju, C., S. NagaMani, G.rakesh Prasad, and S.Sunitha (2011). "Morphological Edge Detection Algorithm Based on Multi-Structure Elements of Different Directions”. International Journal of Information and Communication Technology Research, vol. 1 ( 1 ).

[6] Muthukrishnan, R., M. Radha (2011). "Edge Detection Techniques for Image Segmentation". International Journal of Computer Science and Information Technology, vol. 3 ( 6 ).

[7] Christopher, C.M., K.B. Benjamin (2004). "A Similarity-Based AspectGraph Approach to 3D Object Rrecognition". International Journal of Computer Vision, vol. 57 ( 1 ), 5-22.

[8] Peter, T (2007). "Morphology Image Pre-processing for Thinning Algorithms". Journal of Information, Control and Management Systems, vol. 5 ( 7 ).

[9] Shaosheng, F., W. Hainan (2011). "Multi-direction Fuzzy Morphology Algorithm for Image Edge Detection". Journal of Networks, vol. 6 ( 6 ).

[10] Canny, J. F (1986). "A computational approach to edge detection", .IEEE Trans. Pattern Analysis and Machine Intelligence, pages 679-698.
[11] Manisha, K., S. Arjan, S. Baljit (2010). "Adaptive Thresholding for Edge Detection in Gray Scale Images". International Journal of Engineering Science and Technology, vol. 2 ( 6 ), 2077-2082.

[12] Luo, W (2006). "Comparison for Edge Detection of Colony Images". IJCSNS International Journal of Computer Science and Network Security, vol. 6 (9A).

[13] Hua, S., G. Chen, H. Wei, and Q. Jiang (2012). "Similarity Measure for Image Resizing using SIFT feature". EURASIP Journal on Image and Video Processing.

[14] Chary, R.V.R., D.R. Lakshmi, and K.V.N Sunitha (2012). "Feature Extraction Method for Color Image Similarity". Advanced Computing : An International Journal, vol. 3 ( 2 ).

[15] Meyer, F (2001). "An overview of morphological segmentation". International Journal of Pattern Recognition and Artifcial Intelligence, Vol. 15 (7), 1089-1118.

[16] Kumar, S.H., S. Pooja, and S. Khushboo (2012). "Morphological Segmentation and Gradient of Multispectral Image of Bareilly Region". In IJCA Proceedings on National Conference on Recent Trends in Computing NCRT (3) ,May 7-10.

[17] Veltkamp, R. C. (2001). Shape matching: Similarity measures and algorithms. In Shape Modeling and Applications, SMI International Conference on. (pp. 188-197). IEEE.

[18] Cheong, O., Gudmundsson, J., Kim, H. S., Schymura, D., \& Stehn, F. (2009, June). Measuring the Similarity of Geometric Graphs. In Proceedings of the 8th International Symposium on Experimental Algorithms (pp. 101-112). Springer-Verlag.

[19] Veltkamp, R. C., \& Hagedoorn, M. (2000, November). Shape Similarity Measures, Properties and Constructions. In Proceedings of the 4th International Conference on Advances in Visual Information Systems (pp. 467-476). Springer-Verlag.

[20] Groneman, Isaäc, 2009: 'The Javanese Kris'. Leiden: KITLV Press 